\title{
Programa de Aquisição de Alimentos: a lente bioética na segurança alimentar
}

Luciana Rodriguez Teixeira de Carvalho ${ }^{1}$, Dais Gonçalves Rocha ${ }^{2}$

\section{Resumo}

A bioética alcança questões públicas e busca a garantia dos direitos humanos, dentre os quais aqui se destaca o da alimentação, debate ético de uma situação persistente resultante da exclusão social. O Programa de Aquisição de Alimentos (PAA) busca a construção de proposta de segurança alimentar e nutricional centrada na comercialização da produção, nas pessoas, no social e na segurança alimentar dos mais vulneráveis. Este trabalho objetivou analisar os documentos oficiais do PAA, na modalidade Compra da Agricultura Familiar Com Doação Simultânea, como um programa de segurança alimentar na perspectiva de referenciais bioéticos. Utilizando metodologia de análise de conteúdo foram selecionadas as categorias: direito humano, equidade, proteção, participação e inclusão social. Verificou-se que possuem caráter estruturante para a segurança alimentar, delineando interfaces entre referenciais bioéticos e avanços na garantia dos direitos humanos. Porém, há limitações quanto à participação dos atores envolvidos.

Palavras-chave: Bioética. Segurança alimentar e nutricional. Direitos humanos. Agricultura.

\section{Resumen}

\section{Programa de adquisición de alimentos: la bioética lente de la seguridad alimentaria}

La Bioética alcanza cuestiones públicas y busca la garantía a los derechos humanos, especialmente la comida, debate ético como resultado de una persistente situación de exclusión social. El Programa de Adquisición de Alimentos (PAA) tiene por objeto la construcción de una propuesta de Seguridad Alimentaria u Nutricional centrado en la comercialización de la producción, en las personas, en lo social y en la seguridad alimentaria de los más vulnerables. Este estudio tuvo como objetivo analizar los documentos oficiales del PAA, en la modalidad de Compra de la Agricultura Familiar para la Donación Simultánea como un Programa de Seguridad Alimentaria en perspectiva de referenciales bioéticos. Utilizando la metodología de análisis del contenido se han seleccionado las categorías: Derecho Humano, la equidad, la protección, la participación y la inclusión social. Se encontró que este tiene una tendencia estructural a la seguridad alimentaria, presentando interfaces con los referenciales bioéticos con avances en la garantía de los derechos humanos. Sin embargo, existen limitaciones en el proceso de participación de los actores involucrados.

Palabras-clave: Bioética. Seguridad alimentaria. Derechos humanos. Agricultura.

\section{Abstract \\ The food purchase program: the bioethics`lens on food security}

The Bioethics reaches public matters and seeks the guarantee of the human rights among which is highlighted feeding, an ethical debate on a persistent situation resulting from social exclusion. The Food Purchase Program (FPP) pursues the construction of a food and nutritional security centered on the commercialization of the production, on people, on social and on food security of the most vulnerable. This work aims to analyze the FPP official documents, in the Purchase from Family Agriculture with Simultaneous Donation modality as a Food Security Program in the perspective of bioethics references. Using the Content Analysis Method, it was selected as analysis categories: human rights, equity, protection, participation and social inclusion. It was found that this program has a structuring character to food security, showing interfaces with bioethical references with advances on the guarantee of the human right to food. However, there are limitations regarding the participation process of those involved.

Key words: Bioethics. Food security. Human rights. Agriculture.

1. Mestranda lucianartca@hotmail.com 2. Doutora daisrocha@yahoo.com.br - Universidade de Brasília, Brasília/DF, Brasil.

\section{Correspondência}

Luciana Rodriguez Teixeira de Carvalho - Avenida Flamboyant, Lote 4, Residencial Bem Te Vi, apt ${ }^{\circ} 506$ CEP 71917000 . Águas Claras Norte/ DF, Brasil.

Declaram não haver conflito de interesse. 
É imperativo que a bioética contribua na construção das sociedades que garantam os direitos humanos, pois se fundamenta em uma visão macro, ampliada e seguramente comprometida com a dimensão social. Críticas, politizadas e voltadas à ética aplicada, às novas propostas teóricas da bioética latino-americana buscam incessantemente diminuir as disparidades nas sociedades do continente e em todo o planeta. Considera-se, portanto, determinante que o campo da bioética seja incorporado nos processos de definição das políticas públicas, objetivando sua melhoria considerando, sobretudo, os mais excluídos e necessitados.

Dentre estas formulações recentes em bioética, destaca-se a bioética de intervenção, que incorpora os direitos humanos universais, advogando o reconhecimento do direito coletivo à igualdade mediante a promoção da equidade de indivíduos e grupos sociais, buscando acesso real à construção da cidadania ${ }^{1}$. Garrafa e Porto elaboraram esta proposta a partir da ideia de uma bioética politizada, capaz de tornar-se instrumento de defesa dos direitos humanos. Para tanto, a bioética de intervenção deve se ocupar das situações persistentes, ou seja, com aqueles problemas que continuam acontecendo $e$ que não deveriam mais acontecer no século $X X I^{2}$.

A bioética de proteção, outra proposta latinoamericana, objetiva a efetivação da responsabilidade aberta, assumindo o princípio da responsabilidade de proteção pelo Estado, para que as ações em saúde pública sejam implementadas de modo comprometido e viável ${ }^{3}$. Estudos baseados em levantamento sobre a perspectiva epistemológica das bioéticas brasileiras ${ }^{4}$ indicaram que o princípio da proteção estava direta ou indiretamente presente em todas elas, considerado como papel elementar do Estado.

A Declaração Universal sobre Bioética e Direitos Humanos ${ }^{5}$ apresenta o resultado prático do esforço acadêmico e militante de estudiosos brasileiros e da América Latina na ampliação do campo de ação da bioética. Incorporando, desde seu nome, os direitos humanos como elemento fundamental à reflexão e propostas para a ação bioética, inclui como eixos orientadores a equidade, a justiça, a responsabilidade social, o direito à saúde, dentre outros. Considerando o contexto de iniquidades sociais no Brasil e demais países da América Latina ${ }^{6}$, não se pode pensar em bioética distanciada da defesa dos vulneráveis. Nessa perspectiva, a Declaração consolida-se como marco histórico da bioética, voltando-se à supressão das iniquidades no acesso aos direitos humanos por meio da ética e da justiça social.
Dado o arcabouço teórico destas novas propostas em bioética, bem como da própria Declaração, considera-se pertinente sua utilização para análise de programas de segurança alimentar e nutricional, os quais se debruçam sobre um aspecto inalienável dos direitos humanos, o acesso à alimentação e nutrição. Assim, este artigo objetivou apresentar e discutir os resultados da análise dos documentos oficiais do Programa de Aquisição de Alimentos (PAA), na modalidade Compra da Agricultura Familiar para Doação Simultânea, como um programa de segurança alimentar na perspectiva de referenciais bioéticos.

\section{Parâmetros da bioética}

Ao longo de sua história, a bioética apresentou uma etapa de ampliação conceitual que tem como marco a homologação da Declaração Universal sobre Bioética e Direitos Humanos ${ }^{5}$. Além de confirmar o caráter pluralista e multi-intertransdisciplinar deste campo de estudo, esta Declaração ampliou definitivamente a agenda da bioética para além da temática biomédica-biotecnológica, incluindo as dimensões social e ambiental ${ }^{7}$. Isto pode ser constatado dentre os objetivos da Declaração ${ }^{5}$, dos quais se destaca: iii) promover o respeito pela dignidade humana e proteger os direitos humanos, assegurando o respeito pela vida dos seres humanos e pelas liberdades fundamentais, de forma consistente com a legislação internacional de direitos humanos ${ }^{5}$.

Em artigo de 2005, destinado a apresentar a Declaração, Garrafa afirma o acerto da bioética brasileira por meio das ações desenvolvidas para aproximar decisivamente o campo da saúde pública e a agenda social. Afirma que o conteúdo do documento altera a agenda da bioética, democratizando-a e tornando-a aplicada e comprometida com as populações vulneráveis, as mais necessitadas de ações pautadas na ética aplicada à dimensão e interesses coletivos. Afiança que a Declaração é mais um instrumento à disposição da democracia, no sentido do aperfeiçoamento da cidadania e da aplicação dos direitos humanos universais ${ }^{7}$.

Schramm e Kottow ${ }^{2}$, que inicialmente apresentam a bioética da proteção, definiram esta proposta como sendo voltada à aplicação da responsabilidade social, na qual deve se basear o Estado para assumir suas obrigações para com as populações consideradas em seus contextos reais, que são, ao mesmo tempo, naturais, culturais, sociais e ecoambientais. Lembram, inclusive, que a utilização do 
princípio de proteção é um resgate do papel protetor do Estado, considerado como fundamento moral do Estado mínimo, que dá sustentáculo à legitimidade do Estado de bem-estar contemporâneo.

A bioética da proteção, aprofundada posteriormente a partir da primeira por Schramm, pode ser entendida como a parte da ética aplicada constituída por ferramentas teóricas e práticas que visam entender, descrever e resolver conflitos de interesses entre quem tem os meios que o "capacitam" (ou tornam competente) para realizar sua vida e quem, ao contrário, não os tem ${ }^{8}$. Para definir a quem preferencialmente seria destinada essa proteção, haja vista que os recursos são necessariamente limitados, diferencia vulnerabilidade de vulneração, considerando o último conceito chave para a priorização de políticas públicas em saúde coletiva. Assim, a bioética da proteção volta-se aos grupos literalmente vulnerados que não são capazes, por alguma razão independente de suas vontades, de se defenderem sozinhos pelas condições desfavoráveis em que vivem ou devido ao abandono das instituições vigentes que não lhes oferecem o suporte necessário para enfrentar sua condição e tentar sair dela ${ }^{9}$.

Garrafa e Porto ${ }^{1}$ referem a bioética a partir do enfoque das situações que persistem no debate ético, principalmente aquelas resultantes da exclusão social. Os autores apresentam a bioética de intervenção, formulada com os seguintes propósitos: a) análise contextualizada de conflitos que exijam elegibilidade para uma determinada adequação cultural; b) abordagem de macroproblemas bioéticos persistentes ou cotidianos enfrentados por grande parte da população de países com altos índices de exclusão social como o Brasil e seus vizinhos da América Latina e Caribe ${ }^{10}$.

Propõem que a bioética considere o alijamento das classes sociais diante da concentração de poder, a vulnerabilização de grandes parcelas da sociedade por questões sociais, que envolvem a disparidade histórica de poder entre indivíduos, grupos e segmentos. Garrafa aponta, ainda, a relação dialética entre reflexão e ação, responsabilidade individual e coletiva, pelo impacto que as escolhas dos indivíduos produzem na realidade. Dessa forma, insere novo significado ao conceito de autonomia, vinculando-o à responsabilidade existencial frente à sociedade e à natureza, a responsabilidade compartilhada, levando os sujeitos vulneráveis, sem voz no cenário histórico, a desenvolverem sua autonomia mediante o processo de inclusão social ${ }^{7}$.

Recentemente, Correa ${ }^{11}$, pretendendo fundamentar referenciais básicos para uma bioética social, relacionou a não maleficência com o não abandono social, prevenção em saúde e responsabilidade política; a justiça com a promoção dos direitos, priorização em saúde, monitoramento das desigualdades, discriminação, controle e sustentabilidade do sistema. Estabeleceu relação, ainda, entre autonomia e controle social, participação da comunidade, prevenção e educação e confidencialidade. Por fim, traçou paralelo entre a beneficência e a qualidade do sistema, crédito e subsidiariedade. Estas analogias facilitam a aplicabilidade do principialismo na dimensão coletiva.

Deste breve resumo das mais destacadas propostas teóricas para a bioética brasileira hodierna se depreende que o foco analítico de todas as correntes busca compreender o sentido das ações humanas, seja no campo da vida ou da saúde, utilizando para tanto o conhecimento gerado em diversas áreas como a Filosofia, Sociologia, Psicologia, Antropologia e Comunicação, as quais incorporam estudos empíricos, qualitativos ou quantitativos que propiciam analisar o agir moral. Cabe ressaltar a interface entre a bioética e a saúde coletiva, cuja convergência não ocorre apenas da proximidade de suas temáticas, mas pelo modo e metodologia para abordá-las. Ambas são apresentadas em contexto de ruptura epistemológica, que permitiu compreender suas temáticas de forma ampliada, relacionando a saúde com as ações humanas ${ }^{12}$.

\section{Políticas públicas para a segurança alimentar e nutricional}

No Brasil, as políticas públicas relacionadas com o abastecimento alimentar surgiram em 1930, coincidindo com o processo de industrialização. Em 1938, foi criada pela Lei 399 a chamada "ração tipoessencial mínima" que determinava doze produtos para compor a alimentação básica da população brasileira. Em 1940, foi estabelecido o Serviço Nacional de Alimentação e Previdência Social (Saps), objetivando prover a melhoria das condições nutricionais dos trabalhadores e proporcionar alimentação acessível com a instalação de restaurantes destinados a classe trabalhadora ${ }^{13}$.

De acordo com Silva ${ }^{14}$, o ano de 1945 foi marcante para o desenvolvimento das políticas públicas direcionadas às questões nutricionais da população brasileira, com a criação da Comissão Nacional de Alimentação (CNA), com funções específicas para definir a política nacional de alimentação e estimular estudos referentes aos problemas de alimenta- 
ção, objetivando identificar as deficiências na alimentação da população brasileira. A partir daí, vários programas foram criados no intuito de atender as situações de combate à fome e de prover alimentos para a população.

Até aquele momento, inexistiam políticas de abastecimento alimentar e, em 1972, o governo brasileiro cria o Sistema Nacional de Centrais de Abastecimento (Sinac), que atualmente pode ser comparado à Companhia Nacional de Abastecimento (Conab). Ainda na década de 70, foi criado o Instituto Nacional de Alimentação e Nutrição (Inan), configurando um marco de políticas voltadas para o abastecimento alimentar, direcionadas às pessoas em situação de insegurança alimentar ${ }^{15}$.

Na década de 90, foi criado o Sistema Nacional de Vigilância Alimentar e Nutricional (Sisvan), com o intuito de buscar informações acerca das problemáticas de alimentação e nutrição, bem como levantar a distribuição geográfica das populações em risco alimentar. Em 1991, foi formulada uma proposta de Política Nacional de Segurança Alimentar, que traz estratégias e programas direcionados aos direitos de cidadania e à democracia ${ }^{15}$. Apesar de não ter sido implementada, esta proposta contribuiu para a criação do Conselho Nacional de Segurança Alimentar e incentivou a criação dos conselhos estaduais e municipais de segurança alimentar e nutricional sustentável ${ }^{13}$.

Nesse processo de reconhecimento crescente das políticas e ações para segurança alimentar inscreve-se a Ação da Cidadania e o Plano de Combate à Fome e a Miséria, como novas propostas de combate às iniquidades sociais, seguindo os princípios da descentralização, solidariedade e de parceria entre o Estado e a sociedade ${ }^{16}$. Em 2001, surge o Programa Fome Zero, resultante de um período de mobilização e encontros, nos quais foram reunidos mais de mil participantes, entre técnicos e especialistas da área. Nesta macroproposta está inserida uma política mais estruturada: o Programa de Aquisição de Alimentos (PAA).

O caráter estruturante do PAA está diretamente relacionado à sua importância. Belik ${ }^{17}$ ressalta que políticas estruturais têm o poder de modificar as bases sociais e culturais das populações às quais se destinam. Por meio do desenvolvimento de mecanismos que permitam o acesso a ativos de produção e educação, é possível garantir a melhoria de renda, em bases permanentes, para as populações excluídas.

Em 2006, o Projeto de Lei Orgânica da Segurança Alimentar e Nutricional (Losan), que instituiu o Sistema Nacional de Segurança Alimentar e Nutricional (Sisan), objetivou assegurar de forma sustentável o direito humano à alimentação adequada para toda a população brasileira. Trata-se de um sistema que visa organizar e monitorar ações e programas de diversos setores governamentais e não governamentais, articulando-os em uma política de segurança alimentar e nutricional ${ }^{18}$.

Maluf ${ }^{19}$ afirma que o Sisan estabelece interfaces com sistemas associados e é composto por subsistemas, sendo três os fatores que incidem neste processo: 1) a natureza e a atividade da ação. Há componentes do sistema que demandam um subconjunto articulado de instrumentos de ações, como os circuitos produtivos e comerciais, sistemas de abastecimento alimentar e o sistema de monitoramento das condições nutricionais; 2 ) os programas públicos permanentes. A descentralização desses programas leva à formação de subsistemas associados ao Sisan, como a saúde, alimentação escolar e agricultura familiar e; 3 ) os atores e movimentos sociais. Suas variadas formas de organização, como em redes sociais de solidariedade, associações, cooperativas, entidades etc., geram processos e dinâmicas eventualmente articuladas, cuja amplitude vai além do campo da segurança alimentar e nutricional.

Ao longo do tempo, o marco da política para a garantia da segurança alimentar e nutricional no país e as políticas e programas a ele correlacionados obtiveram consideráveis avanços, objetivando a inclusão de ações tanto do governo quanto da sociedade, as quais, em grande medida, ainda estão sendo desenvolvidas por variados setores. Historicamente, essas ações vêm sendo implementadas na linha de suplementação alimentar, de apoio ao processo de comercialização e produção de alimentos, voltando-se ainda a estimular o enfoque na educação nutricional. Sua consolidação plena, porém, implica em grande desafio, como articular e coordenar as ações ou fazer com que os recursos cheguem aos grupos populacionais mais vulneráveis para promover equidade.

Valente ${ }^{20}$ refere que a noção de segurança alimentar e nutricional inscreve-se dentre os direitos de todo cidadão de estar seguro em relação aos alimentos e à alimentação nos aspectos da suficiência (proteção contra a fome e a desnutrição), qualidade (prevenção de males relacionados com a alimentação) e adequação (apropriação às circunstâncias sociais, ambientais e culturais). Ressalta Maluf ${ }^{20}$ que o direito humano à alimentação deverá ser assegurado por intermédio de políticas de segurança alimentar e nutricional que, por sua vez, são de responsabi- 
lidade do Estado e da sociedade sobre a qual pesam obrigações frente a normas legais universais.

Colocado como crucial para a fruição dos demais direitos, o direito à nutrição adequada, de estar livre da fome e ter acesso à alimentação saudável, integra o conjunto dos direitos dos povos promovidos seja pela Declaração Universal dos Direitos Humanos ${ }^{21}$, pela Emenda Constitucional $64{ }^{22}$, que acrescentou este direito no artigo $6^{\circ}$ da Constituição Federal, ou pelo artigo 14 da Declaração Universal sobre Bioética e Direitos Humanos ${ }^{5}$.

Como visto, os programas de segurança alimentar e nutricional englobam vários outros, mas destaca-se aqui o PAA selecionado para este estudo devido ao seu caráter estruturante dentre as políticas públicas da área no Brasil.

\section{Programa de Aquisição de Alimentos}

O PAA foi instituído pela Lei 10.696 e regulamentado pelo Decreto 4.772 , que determinam que o Estado assuma papel estratégico na comercialização da pequena produção familiar e incentiva a produção agropecuária e a sustentação de preços, adquirindo alimentos produzidos por produtores familiares cadastrados no Programa Nacional de Fortalecimento da Agricultura Familiar (Pronaf), inclusive agroextrativistas, quilombolas, famílias atingidas por barragens, pescadores artesanais, aquiculturas familiares, trabalhadores rurais sem terra acampados e comunidades indígenas, por meio de suas associações ou cooperativas ${ }^{23}$.

O PAA apresenta como objetivo central garantir o acesso aos alimentos em quantidade, qualidade e regularidade necessárias às populações em situação de insegurança alimentar e nutricional e promover a inclusão social no campo, por meio do fortalecimento da agricultura familiar ${ }^{23}$. 0 programa prevê duas etapas importantes: o suprimento alimentar à população e o estímulo à pequena produção e a seu consumo.

O PAA construiu uma proposta de segurança alimentar para o país, considerando o papel decisivo da agricultura familiar. Reconhece a necessidade de integração entre as políticas de fomento à produção e as de abastecimento alimentar, propondo articulaçãolocal de demandas da agricultura familiar, subvenção ao consumo de alimentos às populações que se encontram em insegurança alimentar e gestão integrada entre as políticas emergenciais e estruturais ${ }^{23}$. Sua complexidade de ação e atuação vai além do estímulo à agricultura familiar e elevação da produção rural, perpassando todo o arcabouço estrutural de uma importante questão social e econômica para o país: o desenvolvimento comunitário na área rural, mediante o fortalecimento das organizações locais de agricultores.

O potencial do PAA no processo de enfrentamento da pobreza é considerado a partir da premissa de que favorece a construção de uma rede de proteção social que viabiliza, por meio do desenvolvimento de políticas assistenciais estruturantes, a garantia do patamar básico necessário à elevação dos padrões de qualidade de vida e de promoção do bem-estar coletivo. Consolidar uma rede de proteção e promoção social na agricultura familiar é garantir que as famílias organizadas tenham as mesmas oportunidades, numa linha de ampliação e universalização dos direitos.

A produção dos alimentos é comprada pela Conab, por prefeituras e por alguns estados, sob preço de referência equivalente ao preço de atacado do produto no mercado regional. Para alguns alimentos, o preço é estabelecido pelo Grupo Gestor Interministerial do programa, integrado pela Conab e pelos ministérios da Agricultura, Pecuária e Abastecimento; Fazenda; Planejamento; Desenvolvimento Agrário (MDA) e Desenvolvimento Social e Combate à Fome (MDS). O PAA conta com a participação dos conseIhos municipais de segurança alimentar (Consea), mecanismo de controle social do projeto que confere confiabilidade à sua fiscalização e execução ${ }^{24}$.

A distribuição de renda, o maior controle do espaço rural, a preservação da cultura alimentar regional e o incentivo à economia local e à agrobiodiversidade também estão inseridos dentre os objetivos do PAA. Além do apoio à produção para o autoconsumo, do excedente para a comercialização e do subsídio ao consumo citam-se os benefícios indiretos advindos da recuperação dos preços recebidos pelos produtores. Existem casos em que o simples anúncio da compra pública de determinada quantidade de produto é suficiente para elevar os preços agropecuários, aumentando a remuneração do produtor com a venda no mercado local. Assim, o PAA contribui para a estruturação, organização e planejamento da oferta desse segmento produtivo ${ }^{24}$.

As modalidades da agricultura familiar instituídas pelo PAA são Compra da Agricultura Familiar com Doação Simultânea (CPR-Doação), Compra Direta da Agricultura Familiar (CDAF) e Formação de Estoque (CPR-Estoque) ${ }^{24}$. Neste estudo, abordou-se o PAA na modalidade Compra com Doação Simultânea (CPR-Doação), a qual trouxe importantes mudanças na matriz produtiva das unidades familiares, 
em especial no que concerne à diversificação ${ }^{25}$. 0 programa tem restaurado a policultura porque, em muitas regiões do Brasil, a modernização da agricultura conduziu os agricultores a ingressar na especialização produtiva, na monocultura e na produção de commodities, não raro destinadas ao mercado externo. Isto expôs esses agricultores a contexto de acentuada vulnerabilidade social. Assim, o PAA tem se destacado por incentivar maior diversificação, à medida que conecta a oferta da produção familiar a uma demanda diversificada ${ }^{25}$, principalmente dos próprios agricultores e daqueles que se encontram em insegurança alimentar.

A legislação brasileira tem apoiado as cooperativas de agricultores familiares, protegendo e estabilizando os preços de alimentos básicos, tornando as frutas e os vegetais verdes e outros frescos mais acessíveis e disponíveis e, ainda, bem mais atraentes do que os processados ${ }^{23}$.

\section{Método}

Com metodologia qualitativa, o estudo baseouse na análise de conteúdo proposta por Bardin ${ }^{26}$, trabalhando documentos oficiais do PAA e identificando suas convergências com categorias de referenciais bioéticos preestabelecidos: direito humano (DH); equidade (EQ); proteção (PT); inclusão social (IS) e participação (PA). A abordagem quantitativa considerou a frequência de aparição das categorias e a qualitativa, a presença ou ausência de indicadores não frequenciais, mas propícios a inferências.

Segundo Bardin ${ }^{26}$, as diferentes fases da análise de conteúdo são organizadas em torno de três momentos: a pré-análise, a exploração do material e o tratamento dos resultados. Na pré-análise foram definidos os documentos trabalhados, considerando a base legal do funcionamento do PAA. Foi realizada uma leitura flutuante, deixando-se invadir por impressões e orientações. A seguir, se efetuou uma leitura precisa, em função das categorias estabelecidas.

$\mathrm{Na}$ análise foram utilizados referenciais bioéticos considerados primordiais para permear todo o processo de uma política pública de segurança alimentar e nutricional (SAN).

Considerou-se o referencial direito humano, reconhecido como parte dos direitos e das garantias do ser humano, por meio de sua proteção pelo poder estatal e do estabelecimento de condições mínimas de vida, como o direito humano a alimentar-se.
Outro referencial esteve voltado para a participação efetiva e consciente dos atores-chave envolvidos no PAA e o controle da sociedade sobre as ações do Estado como conquistas democráticas indispensáveis à consolidação dos objetivos de uma política de SAN.

O referencial da proteção foi compreendido como uma atitude de dar abrigo ou cobertura às necessidades essenciais, aquelas que devem ser satisfeitas para que o afetado possa atender a outras necessidades e interesses ${ }^{8}$.

Considerada como o referencial relacionado à necessidade de se "tratar desigualmente os desiguais" de modo a se alcançar a igualdade de oportunidades, de desenvolvimento pessoal e social entre os atores de uma política de SAN, foi utilizada a equidade.

Por sua vez, o referencial bioético da inclusão social passa pelo pressuposto de que uma ação de SAN politicamente comprometida é aquela capaz de transformar a práxis social, gerando novas oportunidades, aumento da renda, alimentação adequada e saúde, dentre outras.

A importância das categorias foi atribuída mediante sua frequência nos documentos como regras de enumeração para análise e, ainda, a medida de intensidade com que cada elemento apareceu como indispensável na avaliação de valores ideológicos presentes no corpus analisado. O material foi codificado por contagem e pela agregação das unidades de registro, sendo selecionadas frases que ilustram a presença da categoria e sua interface com os referenciais bioéticos propostos.

O corpus final do estudo foi o artigo 19 da Lei 10.696/03, que instituiu o Programa; o Capítulo III da Lei $12.512 / 11$, que deu nova redação ao artigo 19 de 2003; o Decreto 6.447/08, que regulamenta o artigo 19 da Lei 10.696/03; a Portaria 47/08, que estabeleceu os procedimentos para a emissão da Declaração de Aptidão ao Programa Nacional de Fortalecimento da Agricultura Familiar; a Portaria 312/06 do Ministério do Desenvolvimento Social, que designou os membros do Grupo Gestor do PAA; a Portaria 111/03 do Ministério da Agricultura, que estabeleceu o acesso das famílias de trabaIhadores rurais sem terra acampados ao PAA, e a Resolução 44/11 do Ministério do Desenvolvimento Social e Combate à Fome (MDS), que fomentou o acesso de mulheres também ao Programa. Este corpus faz parte do marco legal do PAA, abarca a modalidade CPR-Doação na perspectiva dos referenciais em estudo. 


\section{Resultados}

De acordo com a análise da base legal do PAA, verificaram-se convergências entre as categorias propostas e o conteúdo do corpus em estudo. Abaixo, é apresentado o resultado da análise de conteúdo de cada normativo investigado, propiciando sua descrição sucinta. Ressalte-se que as unidades de registro, algumas vezes, abarcaram ao mesmo tempo mais de uma categoria de análise.

O artigo 19 da Lei $10.696^{27}$, que instituiu o PAA, possui convergências em todas as categorias de análise. Dentre estas, a maior frequência se deu na categoria de direito humano, pressuposto essencial da bioética, aqui levado em consideração devido à garantia de alimentação adequada e promoção da segurança alimentar e nutricional serem elencadas dentre estes direitos.

\begin{tabular}{|l|l|}
\hline \multicolumn{1}{|c|}{ Categoria } & \multicolumn{1}{c|}{ Convergência } \\
\hline DH - Direito humano & $\begin{array}{l}\text { "Pessoas em situação de insegurança alimentar" } \\
\text { "Ações de combate à fome" } \\
\text { "Promoção de Segurança Alimentar" }\end{array}$ \\
\hline PT - Proteção & "Incentivar a agricultura familiar" \\
\hline PA - Participação & "Grupo Gestor" \\
\hline IS - Inclusão social & "Incentivar a agricultura familiar" \\
\hline
\end{tabular}

No Capítulo III da Lei $12.512{ }^{28}$, que trata do PAA, observou-se convergências com todas as categorias bioéticas discriminadas no estudo. Frise- se que este capítulo revelou-se o instrumento legal com maior ocorrência dos referenciais bioéticos.

\begin{tabular}{|c|c|}
\hline Categoria & Convergência \\
\hline $\mathrm{DH}$ - Direito humano & $\begin{array}{l}\text { "Alimentos doados a pessoas e famílias em situação de insegurança alimentar" } \\
\text { "Ações de promoção de Segurança Alimentar" } \\
\text { "Doação a pessoa e famílias em situação de insegurança alimentar e nutricional" } \\
\text { "Promover o acesso à alimentação em quantidade, qualidade e regularidade" } \\
\text { "Direito Humano à alimentação saudável e adequada" } \\
\text { "Ações de combate à fome e promoção da Segurança Alimentar e Nutricional" }\end{array}$ \\
\hline EQ-Equidade & $\begin{array}{l}\text { "Critérios para contemplar as especificidades de seus diferentes segmentos e } \\
\text { atendimento dos beneficiários de menor renda" } \\
\text { "Pessoas em insegurança alimentar" } \\
\text { "Priorizar gestantes, nutrizes e crianças" } \\
\text { "Povos indígenas, quilombos rurais" } \\
\text { "Dispensa de licitação" }\end{array}$ \\
\hline PT - Proteção & $\begin{array}{l}\text { "Conselhos de Segurança Alimentar e Nutricional são instâncias de controle } \\
\text { do PAA, ou Conselho de Assistência Social ou Conselho de Desenvolvimento } \\
\text { Sustentável" } \\
\text { "Dispensa de procedimento licitatório" } \\
\text { "Celebração de Termo de Adesão" } \\
\text { "União contribuirá com as despesas de operacionalização" } \\
\text { "Conselhos de Segurança Alimentar e Nutricional - Consea, instâncias de } \\
\text { controle e participação social" } \\
\text { "Apoiar as cooperativas" }\end{array}$ \\
\hline PA - Participação & $\begin{array}{l}\text { "Conselhos de Segurança Alimentar e Nutricional são instâncias de controle } \\
\text { do PAA, ou Conselho de Assistência Social ou Conselho de Desenvolvimento } \\
\text { Sustentável" } \\
\text { "Conselhos de Segurança Alimentar e Nutricional - Consea, instâncias de } \\
\text { controle e participação Social" }\end{array}$ \\
\hline IS - Inclusão social & $\begin{array}{l}\text { "A Companhia Nacional de Abastecimento - Conab realiza ações de articulação } \\
\text { com cooperativas e demais organizações de agricultores familiares" } \\
\text { "Incentivar a agricultura familiar, promovendo a sua inclusão econômica e social" }\end{array}$ \\
\hline
\end{tabular}


Também no Decreto 6.447/08 ${ }^{29}$, que regulamenta o artigo 19 da Lei 10.696, se identificaram convergências com as categorias bioéticas propostas, como se vê a seguir:

\begin{tabular}{|l|l|}
\hline \multicolumn{1}{|c|}{ Categoria } & \multicolumn{1}{c|}{ Convergência } \\
\hline DH - Direito humano & $\begin{array}{l}\text { "Pessoas em situação de insegurança alimentar" } \\
\text { "Doação de alimentos ao Programa de Acesso à Alimentação" }\end{array}$ \\
\hline EQ - Equidade & $\begin{array}{l}\text { "Preços levam em conta as diferenças regionais e a realidade da agricultura } \\
\text { familiar" } \\
\text { "Regiões prioritárias para implantação do programa" } \\
\text { "Grupo Gestor" } \\
\text { "Condições de apoio à formação de estoques" } \\
\text { PT - Proteção }\end{array} \quad \begin{array}{l}\text { "Medidas necessárias para a operacionalização do PAA" } \\
\text { "Seguros do Fundo de Combate e Erradicação da Pobreza" } \\
\text { "Convênios com estados, Distrito Federal e municípios" }\end{array}$ \\
\hline IS - Inclusão social & "Condições de venda dos produtos adquiridos" \\
\hline PA - Participação & "Grupo Gestor" \\
\hline
\end{tabular}

A Portaria 111/03 do Ministério do Desenvolvimento Agrário ${ }^{30}$, que diz respeito à necessidade de proporcionar às famílias de trabalhadores rurais sem terra acampados oportunidades de acesso ao Programa, apresentou convergência com apenas três categorias:

\begin{tabular}{|l|l|}
\hline \multicolumn{1}{|c|}{ Categoria } & \multicolumn{1}{c|}{ Convergência } \\
\hline EQ - Equidade & "Acesso a famílias de trabalhadores rurais acampados" \\
\hline PT - Proteção & "Acesso a famílias de trabalhadores rurais acampados" \\
\hline IS - Inclusão social & "Acesso a famílias de trabalhadores rurais acampados ao PAA" \\
\hline
\end{tabular}

A Portaria 47/08 do Ministério do Desenvolvimento Agrário ${ }^{31}$, que trata das condições de emissão da Declaração de Aptidão ao Programa
Nacional de Fortalecimento da Agricultura Familiar (DAP), também apresentou convergência com apenas três categorias, abaixo descritas.

\begin{tabular}{|l|l|}
\hline \multicolumn{1}{|c|}{ Categoria } & \multicolumn{1}{c|}{ Convergência } \\
\hline EQ - Equidade & $\begin{array}{l}\text { "Beneficiários pescadores artesanais, extrativistas, silvicultores, aquicultores, } \\
\text { quilombolas, indígenas" } \\
\text { "Não cobra quaisquer custos pela emissão da DAP" }\end{array}$ \\
\hline PT - Proteção & $\begin{array}{l}\text { "Declaração de Aptidão ao Programa Nacional de Fortalecimento da Agricultura } \\
\text { Familiar (DAP)" } \\
\text { "Emissão da DAP" }\end{array}$ \\
\hline IS - Inclusão social & $\begin{array}{l}\text { "DAP - permite o acesso às demais políticas públicas dirigidas a essa categoria } \\
\text { de produtores" }\end{array}$ \\
\hline
\end{tabular}

A Portaria 312/06 do Ministério do Desenvolvimento Social e Combate à Fome ${ }^{32}$, que designa os membros participantes do Grupo Gestor, foi o documento que menos apresentou convergências com os referenciais bioéticos propostos, mas, até por essa razão, permitiu a inferência quando da ausência do agricultor familiar em instância necessária de representatividade. 


\begin{tabular}{|l|l|}
\hline \multicolumn{1}{|c|}{ Categoria } & \multicolumn{1}{c|}{ Convergência } \\
\hline PA - Participação & $\begin{array}{l}\text { "Beneficiários pescadores artesanais, extrativistas, silvicultores, aquicultores, } \\
\text { quilombolas, indígenas" } \\
\text { "Não cobra quaisquer custos pela emissão da DAP" }\end{array}$ \\
\hline EQ - Equidade & $\begin{array}{l}\text { "Beneficiários pescadores artesanais, extrativistas, silvicultores, aquicultores, } \\
\text { quilombolas, indígenas" }\end{array}$ \\
\hline
\end{tabular}

Por último, a Resolução 44/11 do $\mathrm{MDS}^{33}$, que fovergência com quatro categorias, identificadas com menta o acesso de mulheres ao PAA, apresentou conpressupostos bioéticos a partir do recorte de gênero:

\begin{tabular}{|l|l|}
\hline \multicolumn{1}{|c|}{ Categoria } & \multicolumn{1}{c|}{ Convergência } \\
\hline DH - Direito humano & "Segurança alimentar e nutricional" \\
\hline "RQ - Equidade & $\begin{array}{l}\text { "Peconhecimento das mulheres" } \\
\text { "Participação de mulheres como critério de priorização na seleção e execução } \\
\text { de propostas" } \\
\text { "40\% e } 30 \% \text { de mulheres do total de produtores fornecedores... caso contrário } \\
\text { justificativa" }\end{array}$ \\
\hline PT - Proteção & $\begin{array}{l}\text { "40\% e 30\% de mulheres do total de produtores fornecedores.... caso contrário } \\
\text { justificativa" }\end{array}$ \\
\hline IS - Inclusão social & "Geração de renda para mulheres" \\
\hline
\end{tabular}

Para facilitar a identificação da convergência entre os pressupostos bioéticos e os documentos analisados, referentes ao Programa de Aquisição de
Alimentos, é apresentado a seguir o Quadro 1, que indica a quantidade de ocorrências em cada documento, permitindo sua comparação.

Quadro 1. Frequência/intensidade de convergências entre categorias bioéticas e documentos da base legal do Programa de Aquisição de Alimentos

\begin{tabular}{|l|c|c|c|c|c|c|}
\hline \multicolumn{1}{|c|}{ Categorias } & DH & EQ & PT & PA & IS & Total \\
\cline { 1 - 8 } \multicolumn{1}{|c|}{ Lei 10.696 de 2/7/2003 - artigo 19 } & 3 & 0 & 1 & 1 & 1 & 6 \\
\hline Lei 12.512 de 14/10/2011 - capítulo III & 6 & 5 & 6 & 2 & 2 & 21 \\
\hline Decreto 6.447 de 7/5/2008 & 2 & 2 & 6 & 1 & 1 & 12 \\
\hline Portaria MDA 111 de 26/11/2008 & 0 & 1 & 1 & 0 & 1 & 3 \\
\hline Portaria MDA 47 de 26/11/2008 & 0 & 2 & 2 & 0 & 1 & 5 \\
\hline Portaria MDS 312 de 25/9/2006 & 0 & 1 & 0 & 1 & 0 & 2 \\
\hline Resolução MDS 44 de 16/8/2011 & 1 & 3 & 1 & 0 & 1 & 6 \\
\hline Frequência de aparições/intensidade & $\mathbf{1 2}$ & $\mathbf{1 4}$ & $\mathbf{1 7}$ & $\mathbf{5}$ & $\mathbf{7}$ & $\mathbf{5 5}$ \\
\hline
\end{tabular}

\section{Discussão}

A bioética fomentada no contexto latino-americano é ferramenta que se dispõe a resolver conflitos éticos a partir de uma análise mais ampla e complexa da realidade, tendo por base os direitos humanos, considerando a situação social e econômica dos envolvidos. Atua na esfera pública, quer por meio da intervenção na situação social dos excluídos quer pela responsabilização do Estado em sua proteção. Como lembra Schramm ${ }^{34}$, a utilização ora feita do princípio de proteção em bioética resgata o papel protetor do Estado.
Após análise do marco legal do PAA, o princípio de proteção apresentou-se como o referencial com maior quantitativo de convergências, o que permite a justificação e a análise de políticas públicas ao requerer a clara identificação dos objetivos e dos atores envolvidos em sua implementação, assim como a especificação dos meios adequados para sua execução. Politizada e social, a bioética possui um enfoque direcionado ao papel do Estado na proteção dos vulneráveis e excluídos ou na intervenção do Estado e da sociedade na construção de políticas públicas voltadas a assegurar tais direitos. Qualquer dessas correntes teóricas visa uma bioé- 
tica que forneça mecanismos de mudanças sociais efetivas.

Recine ${ }^{35}$ refere que a análise de programas de segurança alimentar e nutricional tradicional baseada, por exemplo, na cobertura e aplicação de recursos é importante, mas não suficiente, pois são necessárias três outras dimensões para o monitoramento e avaliação das ações que objetivam realizar o direito humano à alimentação e garantia da segurança alimentar e nutricional.

A primeira dimensão diz respeito à máxima adotada pelos defensores dos direitos humanos, considerando que na realização desses direitos o processo é tão importante quanto o resultado. Por "máxima" são compreendidos os princípios orientadores para a garantia do direito humano à alimentação, como, por exemplo, o atendimento prioritário aos vulnerados para promoção da equidade e inclusão social; seu empoderamento por meio da participação ativa e informada nas tomadas de decisão, sem que sejam vitimizados por processos discriminatórios.

Também fazem parte da definição dessa máxima a eficiência; a transparência e a publicidade das decisões e processos; a prestação de contas e a definição clara de responsabilidades; a disponibilidade de mecanismos de monitoramento e de instrumentos de cobrança de direitos (exigibilidade). Recine afirma, ainda, que a partir destes princípios é possível se fazer a análise de uma ação pública não apenas por seu resultado stricto sensu, mas pelo quanto contribuiu para gerar autonomia, participação e equidade, dentre outros aspectos.

A segunda dimensão de análise considera o atendimento de dois aspectos indissociáveis do direito humano à alimentação: o de estar livre da fome e da desnutrição e de ter acesso a uma alimentação adequada. Quanto à terceira dimensão da referida autora, é aquela referente às obrigações que o Estado tem em relação aos direitos humanos em geral e ao direito humano à alimentação adequada. O PAA responde a estas demandas, pois parte de seu objetivo central é garantir o acesso aos alimentos em quantidade, qualidade e regularidade necessárias às populações em situação de insegurança alimentar e nutricional ${ }^{23}$. Nesse sentido, sua adequação às categorias bioéticas, direitos humanos, equidade e proteção é incontestável, podendo-se, por isso, afirmar que esta política pública coaduna-se aos princípios éticos.

No âmbito normativo do PAA, constatou-se que objetiva promover a inclusão social no campo por meio do fortalecimento da agricultura familiar ${ }^{23}$, contribuindo para aumentar a oferta de alimentos produzidos e promover a autonomia das famílias produtoras. Tendo em vista este aspecto, inerente à terceira dimensão analisada por Recine, cabe considerar que é preciso associar o objetivo da política de segurança alimentar e nutricional com estratégias mais amplas de desenvolvimento econômico e social que venham a garantir a equidade e a inclusão social para todos ${ }^{36}$. Cabe aqui destacar que o direito humano à alimentação, saúde, vestuário, trabalho e renda são pressupostos mínimos de inclusão social.

Neste estudo se atribuiu supremacia ao referencial do direito humano fundamentado na primeira dimensão de análise de Recine, por entender que o acesso ao alimento constitui condição elementar para a concretização de todos os outros referenciais, uma vez que o direito à alimentação é condição para a própria vida.

Mesmo tendo em vista que esta análise da base legal do programa demonstrou convergências com os referenciais da equidade e da inclusão social, é indispensável fortalecer tais aspectos por meio de ações intersetoriais de governo que possam assegurar condições fundamentais como o crédito ao pequeno produtor agrícola, bem como as destinadas a implementar a infraestrutura indispensável à produção. Destaca-se que o referencial da equidade está fortalecido no corpus em estudo.

Percebe-se, portanto, que o programa age em duas etapas importantes: a do suprimento alimentar à população vulnerada, que se encontra em insegurança alimentar, e o momento produtivo, incluindo a destinação ao consumo. Se a primeira destas etapas é plenamente atendida, ao menos nas bases legais do Programa, a segunda deixa a desejar em pelo menos dois aspectos, discutidos a seguir.

Garrafa $^{7}$ indica que a inclusão social é inerente ao cidadão emancipado, o qual reflete de maneira efetiva a sua autonomia. A inclusão é fruto da conquista do direito de decidir e da real possibilidade de exercício desse direito e não pode decorrer de mera concessão. O autor explica que para a bioética de intervenção a inclusão social é $a$ ação cotidiana de pessoas concretas e precisa ser tomada na dimensão política, como um processo no qual os atores sociais articulam suas próprias ações ${ }^{7}$. Considerando tal necessidade, a análise bioética da base legal do PAA demonstra que essa articulação necessita ser aprimorada no contexto da política de segurança alimentar, no que concerne à representatividade do agricultor familiar nas instâncias de tomadas de decisão. 
Tal como se pode depreender da análise dos documentos, o princípio da participação não se apresenta de forma ativa e informada, bem como não garante a disponibilidade de instrumentos necessários de recursos que possibilitem efetivamente esta participação. Portanto, aprimorar a participação dos atores sociais envolvidos nas políticas públicas é de grande relevância, pois sem ela esta política continuará sendo construída verticalmente, objetivando fazer para eles e não com eles, o que trará grande possibilidade de não alcançar os resultados esperados. Para tanto, é necessária a participação de todos: as diferentes instâncias de governo, a sociedade civil, os movimentos sociais, as instituições de pesquisa, os formadores de opinião e a comunidade internacional. É com a participação de todos, incluindo aqueles diretamente interessados, que se alcança a equidade e a inclusão social de cada um.

O Estado deve buscar meios para estimular indivíduos e famílias a recuperar a capacidade de conquistar o próprio sustento. Esta é uma das propostas de alcance deste PAA, vez que defende um compromisso político e ético com valores primordiais como a promoção da alimentação. Os documentos analisados mostram a potencialidade do princípio da proteção no Programa, reforçando o papel do Estado em políticas públicas de segurança alimentar e nutricional de forma ativa, necessidade premente para que o direito humano à alimentação possa ser realidade. Entretanto, verifica-se a necessidade de introduzir nesta política mais um degrau, estabelecendo uma atuação articulada com outros setores governamentais para estimular a autonomia dos indivíduos e grupos e garantir sua efetiva emancipação. Só assim se estará rompendo com o ciclo de pobreza e dependência, que são marcas da vulneração.

Apesar desta ressalva, pode-se perceber que o PAA constitui uma resposta estruturante no campo da segurança alimentar e nutricional, voltando-se, prioritariamente, à garantia do direito à alimentação. Tal constatação confirma a afinidade com os referenciais e pressupostos bioéticos, como os direitos humanos, a equidade, a proteção, a inclusão social e participação social. Mesmo considerando as limitações já indicadas, as convergências demonstraram que os referenciais analisados estão inseridos no âmbito da base legal do PAA, constatação que estimula empreender esforços para seu aperfeiçoamento.

\section{Considerações finais}

Políticas públicas para a promoção da segurança alimentar são legítimas e necessárias em uma sociedade que ainda convive com desigualdades inaceitáveis. Este quadro torna necessário e imprescindível adotar ações estruturantes no campo da proteção e da promoção dos direitos humanos, contribuindo para que pessoas e famílias tenham assegurada a plenitude de seus direitos, dentre eles o direito fundamental de alimentar-se adequadamente.

A análise empreendida neste estudo dos instrumentos legais e normativos norteadores das políticas públicas brasileiras voltadas à segurança alimentar e nutricional, especificamente o PAA, por meio de pressupostos e categorias bioéticas, evidenciou concomitantemente tanto a importância e legitimidade ética deste tipo de programa para transformar essa adversa realidade social quanto a pertinência das próprias categorias utilizadas pelas perspectivas bioéticas brasileiras e latino-americanas para analisar tal realidade, indicando que são instrumentos adequados à formulação de políticas públicas que venham ao encontro da ética aplicada e à realidade social.

A utilização dos referenciais bioéticos na análise de políticas públicas de segurança alimentar e nutricional permite identificar os fatores potencializadores e, ainda, sinalizar suas dificuldades, possibilitando a proposição de aditivos em suas bases legais, além de mudanças em ações administrativas, o que possibilitará avanços não só para a realização do direito humano à alimentação adequada, mas, inclusive, para os aspectos relacionados à autonomia, participação e inclusão social, tornando-as mais justas e equânimes.

Cabe ressaltar que a despeito dos avanços do marco legal e da recente produção na investigação das interfaces entre bioética, políticas de saúde e saúde coletiva, consideram-se ainda incipientes as publicações voltadas às políticas de alimentação e nutrição. Em decorrência, sugere-se novos estudos que aprofundem a discussão bioética da temática, voltados, principalmente, à aplicabilidade na área.

Nesse sentido, pretende-se que os resultados deste estudo, baseados nas unidades de análises propostas (de equidade, do direito humano, da proteção, da inclusão social e da participação), propiciem subsídios aos atores sociais envolvidos, funda- 
mentando sua reflexão para aprimorar o programa. Com os resultados convertidos em ação poder-se-á obter olhares diferenciados e, assim, aperfeiçoar o processo de tomada de decisão no desenvolvimento destas políticas.

Ao divulgar os resultados desta pesquisa espera-se evidenciar que os referenciais bioéticos, quando aplicados nas políticas de segurança alimen- tar, possibilitam sua melhor compreensão e aprimoramento. Esta análise do arcabouço normativo do PAA atende às demandas dos autores da área da avaliação das políticas e programas de promoção da saúde ${ }^{36,37}$, os quais, reiteradamente, destacam a importância deste tipo de estudo, que permite refletir acerca do desenho, explicitando as potencialidades e limitações dos valores que fundamentam sua formulação.

\section{Referências}

1. Garrafa V, Porto D. Bioética, poder e injustiça: por uma bioética de intervenção. Mundo Saúde (Impr.). 2002;26(1):6-15.

2. Garrafa V, Porto D. Op. cit. p. 6.

3. Schramm FR, Kottow M. Princípios bioéticos en salud pública: limitaciones y propuestas. Cad Saúde Pública. 2001;17(4):949-56.

4. Oliveira AAS, Villapouca KC, Barroso W. Perspectivas epistemológicas da bioética brasileira a partir da teoria de Thomas Kuhn. In: Garrafa V, Cordon J, organizadores. Pesquisa em bioética no Brasil de hoje. São Paulo: Gaia; 2006. p. 19-44.

5. Organização das Nações Unidas para a Educação, a Ciência e a Cultura. Declaração Universal sobre Bioética e Direitos Humanos. Unesco; 2005 [acesso 14 jul. 2011]. Disponível: www.bioetica. catedraunesco.unb.br

6. Cotta RMM, Gomes AP, Maia TM, Magalhães KA, Marques ES, Batista RS. Pobreza, injustiça, e desigualdade social: repensando a formação de profissionais de saúde. Rev Bras Educ Med. [Internet]. 2007 [acesso 20 dez. 2102];31(3):278-86. Disponível: http://www.scielo.br/scielo. php?script=sci_arttext\&pid=S0100-55022007000300010\&lng=en\&nrm=iso

7. Garrafa V. Inclusão social no contexto político da bioética. Revista Brasileira de Bioética. 2005;1(2):122-32.

8. Schramm FR. Bioética da proteção: ferramenta válida para enfrentar problemas morais na era da globalização. Rev. bioét. (Impr.). 2008;16(1):11-23.

9. Schramm FR. Op. cit. p. 17.

10. Garrafa V, Porto D. Op. cit. p.8.

11. Correa FJL. Princípios para una bioética clínica social. Revista Bioethikos. 2009;3(1):18-25.

12. Junges JR, Zoboli ELCP. Bioética e saúde coletiva: convergências epistemológicas. Ciência e Saúde Coletiva. 2012;17(4):1.049-60.

13. Vasconcelos FAG. Combate à fome no Brasil: uma análise histórica de Vargas a Lula. Rev Nutr. 2005;8(4):439-57.

14. Silva JG. A nova dinâmica da agricultura brasileira. Campinas: IE Unicamp; 1996.

15. Pessanha LDR. Segurança alimentar como princípio orientador de políticas públicas: implicações e conexões para o caso brasileiro [tese]. Rio de Janeiro: Uferj; 1998.

16. Conselho Nacional de Segurança Alimentar e Nutricional. Direito humano à alimentação adequada (DHAA). Consea. [acesso 17 out. 2011]. Disponível: http://www4.planalto.gov.br/ consea/consea-2/direito-humano-a-alimentacao-adequada

17. Belik W. As várias dimensões da fome. Jornal da Unicamp. [Internet]. 12-25 jun. 2006 [acesso out. 2011]:2. Disponível: http://www.unicamp.br/unicamp/unicamp_hoje/jornalPDF/ju327pg02.pdf

18. Hirai WG. Segurança alimentar em tempos de (in)sustentabilidades produzidas. Jundiaí: Paco Editorial; 2011.

19. Maluf RSJ. Segurança alimentar e nutricional. Petrópolis: Vozes; 2007.

20. Valente FLS. Direito humano à alimentação: desafios e conquistas. São Paulo: Cortez; 2002.

21. Nações Unidas. Declaração Universal dos Direitos Humanos. Adotada e proclamada pela resolução 217 A (III) da Assembleia Geral das Nações Unidas em 10 de dezembro de 1948. [Internet]. [acesso out. 2011]. Disponível: http://portal.mj.gov.br/sedh/ct/legis_intern/ddh_bib_ inter_universal.htm

22. Brasil. Emenda Constitucional $n^{\circ} 64$, de 4 de fevereiro de 2010. [Internet]. Altera o art. $6^{\circ}$ da Constituição Federal, para introduzir a alimentação como direito social. Diário Oficial da União. 4 fev. 2010 [acesso out. 2011]. Disponível: http://www.planalto.gov.br/ccivil_03/constituicao/ Emendas/Emc/emc64.htm

23. Brasil. Ministério do Desenvolvimento Social e Combate à Fome. Programa de Aquisição de Alimentos - PAA. [acesso 16 jul. 2011]. Disponível: http://www.mds.gov.br/segurancaalimentar/ aquisicao-e-comercializacao-da-agricultura-familiar 
24. Vieira DFA, Viana CAS. O Programa de Aquisição de Alimentos - PAA e sua relação com o modo de funcionamento da agricultura familiar. [Internet]. [acesso 17 jul. 2011]. Disponível: http://www. conab.gov.br/OlalaCMS/uploads/arquivos/98d489686768a24d24fa7f0d1acabf81.pdf

25. Grisa C, Schmitt CJ, Mattei LF, Maluf RS, Leite SP. Contribuições do Programa de Aquisição de Alimentos à segurança alimentar e nutricional e à criação de mercados para a agricultura familiar. Agriculturas. 2011;8(3):34-41.

26. Bardin L. Análise de conteúdo. São Paulo: Edições 70; 2011.

27. Brasil. Lei n 10.696, de 2 de julho de 2003. [Internet]. Dispõe sobre a repactuação e o alongamento de dívidas oriundas de operações de crédito rural e dá outras providências. 3 jul. 2003 [acesso 7 jul. 2011]. Disponível: http://www.planalto.gov.br/ccivil_03/leis/2003//10.696.htm

28. Brasil. Lei $\mathrm{n}^{\circ}$ 12.512, de 14 de outubro de 2011. [Internet]. Institui o Programa de Apoio à Conservação Ambiental e o Programa de Fomento às Atividades Produtivas Rurais; altera as Leis $\mathrm{n}^{\circ}$ 10.696, de 2 de julho de 2003, 10.836, de 9 de janeiro de 2004, e 11.326, de 24 de julho de 2006. 17 out. 2011 [acesso 7 jul. 2011]. Disponível: http://www.planalto.gov.br/ccivil_03/_ Ato2011-2014/2011/Lei/L12512.htm

29. Brasil. Decreto $n^{\circ} 6.447$, de 7 de maio de 2008. Regulamenta o artigo 19 da Lei $n^{\circ} 10.696$, de 2 de julho de 2003. Institui o Programa de Aquisição de Alimentos. 8 maio 2008 [acesso 7 jul. 2011] Disponível: http://www.planalto.gov.br/ccivil_03/_Ato2007-2010/2008/Decreto/D6447

30. Brasil. Ministério do Desenvolvimento Agrário. Portaria MDA n 111, de 20 de novembro de 2003. Declara que os trabalhadores rurais sem terra acampados se incluem no Programa de Aquisição de Alimentos - PAA, de que trata o art. 19 da Lei $n^{\circ}$ 10.696, de 2 de julho de 2003. Brasília: Diário Oficial da União; 21 nov. 2003 [acesso jul. 2011].Disponível: http://www.conab.gov.br/OlalaCMS/ uploads/arquivos/8acbd3cadc2e2dfa2999b22e8f072e88.pdf

31. Brasil. Ministério da Agricultura. Portaria $n^{\circ} 47$, de 26 de novembro de 2008. Dispõe sobre o regulamento e as condições para realização das operações de crédito de rural ao amparo do Programa Nacional de Fortalecimento da Agricultura Familiar - Pronaf, em especial no que se refere a identificação do agricultor familiar, resolve estabelecer as seguintes condições e procedimentos para emissão de Declaração de Aptidão ao Pronaf. Diário Oficial da União. 27 nov. 2008;(231): Seção I, p. 122-3.

32. Brasil. Ministério do Desenvolvimento Social. Portaria $n^{\circ} 312$, de 25 de setembro de 2006. Designa os membros do Grupo Gestor do Programa de Aquisição de Alimentos, de que trata o Decreto $n^{\circ}$ 5.873, de 15 de agosto de 2006. Diário Oficial da União. 29 set. 2006;(188.): Seção II, p. 36.

33. Brasil. Ministério do Desenvolvimento Social. Resolução $n^{\circ} 44$, de 16 de agosto de 2011. Fomenta acesso de mulheres ao Programa de Aquisição de Alimentos. Diário Oficial da União. 17 ago. 2011;(158): Seção I, p. 92.

34. Schramm FR. A bioética da proteção na saúde pública. In: Fortes PAC, Zoboli ELCP, organizadores. Bioética e saúde pública. São Paulo: Loyola /Centro Universitário São Camilo; 2003. p. 71-83.

35. Recine E. Políticas públicas e a realização do direito humano à alimentação adequada. In: Conselho Nacional de Segurança Alimentar e Nutricional. A segurança alimentar e nutricional e o direito humano à alimentação adequada no Brasil: realização, indicadores e monitoramento da Constituição de 1988 aos dias atuais. Brasília: Consea; 2010. p. 219.

36. Salazar LM. Reflexiones y posiciones alrededor de la evaluación de intervenciones complejas. Santiago de Cali: Programa Editorial Universidad del Valle; 2011.

37. Potvin L, McQueen D, Anderson L, Hartz Z, Salazar LM. Health promotion evaluation practices in the Americas: values and research. New York: Springer; 2008.

\section{Participação dos autores}

Luciana Rodriguez Teixeira de Carvalho concebeu o trabalho e redigiu o artigo. Dais Gonçalves Rocha orientou o trabalho, participando também da análise dos resultados e revisão da redação final.

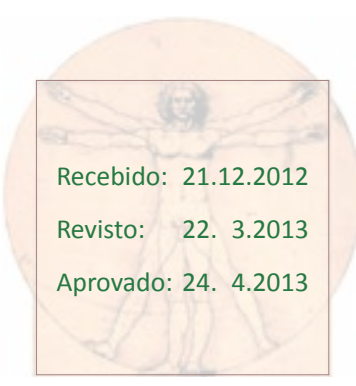

